\title{
Impact of nutritional labelling on 10-d energy intake, appetite perceptions and attitudes towards food
}

\author{
Elise Carbonneau ${ }^{1}$, Julie Perron ${ }^{1}$, Vicky Drapeau ${ }^{2}$, Benoît Lamarche ${ }^{1}$, Éric Doucet $^{3}$, Sonia Pomerleau ${ }^{1}$ \\ and Véronique Provencher ${ }^{1 *}$ \\ ${ }^{1}$ Institute of Nutrition and Functional Foods, Laval University, Quebec, QC, Canada G1V OAG \\ ${ }^{2}$ Department of Physical Education, Laval University, Quebec, QC, Canada G1V OAC \\ ${ }^{3}$ School of Human Kinetics, University of Ottawa, Ottawa, ON, Canada K1N $6 N 5$
}

(Submitted 25 March 2015 - Final revision received 3 September 2015 - Accepted 4 September 2015 - First published online 6 October 2015)

\section{Abstract}

The purpose of this study was to investigate the impact of nutritional labelling on energy intake, appetite perceptions and attitudes towards food. During a 10-d period, seventy normal-weight $\left(\mathrm{BMI}<25 \mathrm{~kg} / \mathrm{m}^{2}\right)$ and seventy-one obese women $\left(\mathrm{BMI} \geq 30 \mathrm{~kg} / \mathrm{m}^{2}\right)$ were given three meals per $\mathrm{d}$ under ad libitum conditions. Participants were randomly assigned to one of three experimental labelling groups in which the only difference was the label posted on lunch meal entrée: (1) low-fat label, (2) energy label (energy content of the entrée and average daily needs) and (3) no label (control). Average energy intake was calculated by weighing all foods before $v$. after daily consumption. Hunger and fullness perceptions were rated on visual analogue scales immediately before and after each meal. Satiety efficiency was assessed through the calculation of the satiety quotient (SQ). The appreciation and perceived healthiness of the lunch entrées were rated on eight-point Likert scales. There was no difference in energy intake, SQ and attitudes towards food between the three labelling groups. Fasting hunger perception was higher in the low-fat label group compared with the two others groups $(P=0.0037)$. No interactions between labelling groups and BMI categories were observed. In conclusion, although labelling does not seem to influence energy intake, a low-fat label may increase women's fasting hunger perceptions compared with an energy label or no label.

Key words: Nutritional labelling: Energy intake: Appetite perceptions: Hunger: Fullness: Appreciation: Body weight

Nutritional labelling has been targeted as a key tool to inform and help individuals in improving eating habits ${ }^{(1-3)}$. Grocery food packages are now supplemented by a variety of nutrition labels ${ }^{(4,5)}$. Nutrient-content claims are the most prevalent type of nutritional labelling, which is voluntarily provided by the food industry, and is targeting mostly fat content ${ }^{(6)}$. Energy posting is also an emerging type of nutritional labelling. In the USA, menu labelling is mandatory at point-of-purchase in restaurant chains in certain cities ${ }^{(2,7)}$, and it is promoted in other countries ${ }^{(8,9)}$. However, studies do not yet clearly support the efficacy of these food-labelling strategies in changing consumers' food choices and intake. Evidence suggests that nutrient-content claims could contribute to overeating ${ }^{(10,11)}$, particularly among overweight individuals ${ }^{(11,12)}$, or have no impact on energy intake ${ }^{(11-14)}$. Energy posting may also be relatively ineffective in promoting healthier food choices ${ }^{(15)}$. A recent systematic review and meta-analysis has established that menu labelling with energy content alone does not have the intended effect of decreasing calories selected or consumed $^{(16)}$. There is thus an urgent need to better understand the impact of nutritional labelling on food intake, more importantly on measured energy intake over several consecutive days. To our knowledge, no studies have yet assessed the impact of nutrition labelling on measured energy intakes for more than one meal and during several days. Considering that women ${ }^{(17,18)}$ and overweight individuals ${ }^{(19)}$ seem to use food labels more often and be more responsive to nutrition information, it is also relevant to better understand whether nutritional labelling influences food intake differently in these individuals.

Furthermore, pre- and post-meal appetite sensations, which reflect objective components of appetite control ${ }^{(20)}$, have been associated with energy intake and have been used to predict subsequent food intake in several studies ${ }^{(21-24)}$. Some evidence suggests that food stereotypes may have an impact on appetite sensations. Unhealthy foods can indeed be perceived as providing more energy than healthy foods, and therefore they may be expected or perceived as more satiating ${ }^{(25,26)}$. However, less is known about the impact of nutritional labelling on appetite perceptions (AP) and satiety efficiency.

\footnotetext{
Abbreviations: AP, appetite perceptions; SQ, satiety quotient.
}

* Corresponding author: V. Provencher, fax +1 418656 5877, email veronique.provencher@fsaa.ulaval.ca 
Appetite sensations may also vary according to weight status. For example, it has been reported that some obese individuals express a lower satiety efficiency - that is a lower change in appetite sensation in response to a test meal ${ }^{(27,28)}$. When being overfed, normal-weight individuals showed reduced pre-meal hunger and increased post-meal satiety compared with reduced-obese participants, whose appetite sensations did not change ${ }^{(29)}$. However, other studies have suggested that this phenomenon may be independent of $\mathrm{BMI}^{(30)}$. Moreover, among a college-aged sample, overweight individuals were more likely to use external cues (i.e. food environment) to determine when they were finished with a meal and less likely to use internal cues (i.e. appetite sensations), compared with normal-weight individuals ${ }^{(31)}$. Another study reported that among obese men and women only $20 \%$ of the eating episodes were initiated because of hunger ${ }^{(32)}$. Considering nutritional labelling as an external cue from the food environment, it thus becomes relevant to investigate the impact of weight status on both intake and AP in the presence of nutrition claims.

Food appreciation and perceived healthiness are also important factors that influence food choices and intake ${ }^{(33)}$. In that regard, studies have shown that fat-related claims and energy posting can influence healthiness perception ${ }^{(34-38)}$, which can have an impact on consumers' food appreciation. When comparing the same food, whether labelled as low fat or regular, Ebneter et al. ${ }^{(13)}$ observed that the regular version was rated as better tasting when participants were aware of the energy content. However, the opposite result was observed when the energy content was not presented. Bowen et al. ${ }^{(39)}$ also reported a better appreciation of a milkshake labelled as low fat $v$. regular, whereas Roefs \& Jansen ${ }^{(40)}$ reported no difference in the palatability of the two food products. According to Ebneter et $a l^{(13)}$, different types of nutritional labelling can have different impacts on perceptions, where a fat content label could be a more powerful determinant of the healthiness assessment than an energy content label. The associations between nutritional labelling, healthiness perception and food appreciation thus remain to be clarified.

Habituation is a form of learning in which a decrease in responsiveness is observed upon repeated exposure to a stimulus ${ }^{(41)}$. It is known that food variety is related to increased energy intake and that repeated exposure to the same food for several days is associated with decreased food intake ${ }^{(41-43)}$. The extent to which repeated exposure to various food labels can lead to habituation, hence modifying their effect on food intake, is currently unknown.

The primary objective of this study is to compare the impact of two labels (low-fat label and energy label) $v$. no label on energy intake as a primary outcome, as well as on AP, meals' appreciation and healthiness perception as secondary outcomes, over a 10-d period among women. We further examined whether body weight (normal weight $v$. obese) and habituation (first $3 \mathrm{~d} v$. last $3 \mathrm{~d}$ of exposure) modify the impact of labelling on food intake, AP, meals' appreciation and healthiness perception. Our prediction is that being exposed to a low-fat label increases 10-d mean energy intake, whereas presenting energy information does not influence energy intake. We also predict that this increased intake in the low-fat label group is not associated with higher fullness, and therefore women in that group have lower satiety efficiency than women in the energy label and the no-label groups. Finally, we predict that meals in the low-fat label and the energy label groups are perceived as healthier, but they are less appreciated than meals in the no-label group.

\section{Methods}

\section{Participants}

Between September 2011 and May 2013, 160 women were recruited in the Quebec City metropolitan area through different media. Eligibility to participate in the study was determined by a phone interview. Women had to be aged 25-65 years, to have a normal weight $\left(\mathrm{BMI}<25 \mathrm{~kg} / \mathrm{m}^{2}\right)$ or to be obese $\left(\mathrm{BMI} \geq 30 \mathrm{~kg} / \mathrm{m}^{2}\right)$, to have a stable weight $( \pm 2.5 \mathrm{~kg})$ in the last 3 months, to take no medication (e.g. corticosteroids, tricyclic antidepressants, atypical antipsychotics) or to have no chronic health problems (e.g. food allergies, eating disorders, diabetes, hyperthyroidism) that could affect weight, appetite measurements and food intake, and were not pregnant or lactating. A food questionnaire was used to ensure at least a moderate appreciation $(\geq 3$ on a five-point Likert scale) of $95 \%$ of the food items offered in the menu and the willingness to consume the food. Participants had to keep a stable level of physical activity throughout the study. Of the 160 participants recruited, three participants dropped out: one left the study before the experimental period because she considered that the study would require too much time and the two others dropped out after a few days of experimentation, because of non-appreciation of the meals and for family reasons. Those two participants were included in the analyses, as a few days were completed and questionnaires were filled out. Moreover, fifteen women whose weight respected the eligibility criteria at phone screening were not included in the analyses because their measured BMI was between 25 and $30 \mathrm{~kg} / \mathrm{m}^{2}$. Three participants were excluded from the analyses because of intention to gain weight ( $n 1$ ), and not having seen the labels ( $n$ 2). Therefore, 141 participants were included in the analyses. This study was conducted according to the guidelines laid down in the Declaration of Helsinki, and all procedures involving human subjects were approved by the Laval University Ethics Committee. Written informed consent was obtained from all subjects. The study was registered in the Clinical Trials.gov registry (NCT01604954).

\section{Overview of the study design and procedures}

During a 10-d period, participants received three ad libitum take-home meals per $\mathrm{d}$ that correspond to $150 \%$ of their estimated daily energy requirements (see details below). We decided to offer an ad libitum diet to ensure that participant's food intake would not be limited by portion size and that participants could consume as much as they wanted. In addition, it has been reported that typical portion size when eating out is usually exceeding the recommendation ${ }^{(44)}$. Participants were aware that they were given large servings of each food, but they were free to eat as little or as much as they 
wanted. Participants were not allowed to eat or drink anything else than what they were given, except for water, tea or coffee (maximum of two black teas or coffees per d, without cream or sugar added). Participants in each weight group (normal weight and obese) were randomly assigned to one of three experimental labelling groups (low-fat label, energy label or no label) as per a parallel study design. The meals were identical across all three label groups; the only difference was the nutritional information provided on the package of the lunch meal entrée on a $7 \times 2.5 \mathrm{~cm}$ label. In the low-fat label group, subjects were informed that the main course was 'low in fat' and provided ' $0 \mathrm{~g}$ of trans fat'. In the energy label group, the energetic content of the main course and average daily needs were indicated on the label (e.g. 'rice and chicken salad contains $1443.5 \mathrm{~kJ} / 250 \mathrm{ml}(345 \mathrm{kcal} / 250 \mathrm{ml})$ portion. An adult should eat $8368 \mathrm{~kJ} / \mathrm{d}(2000 \mathrm{cal} / \mathrm{d})$ '). Subjects in the third group (no-label group) had no information on their meals. Note that participants were blinded to the real study objectives. They were told that this study aimed to rate the appreciation of a new $7-\mathrm{d}$ cyclic menu over a 10-d period (see online Supplementary Appendix for detail on menus and macronutrient content of diets). Meals served on the first $3 \mathrm{~d}$ of the experiment were the same as those served on days 8 through 10 .

\section{Anthropometric measurements, energy needs and energy intake}

At baseline $(T=1)$, participants' height and weight were measured, and weight categorisation was established using BMI calculations $\left(\mathrm{kg} / \mathrm{m}^{2}\right.$ ) (normal weight: $\mathrm{BMI}<25 \mathrm{~kg} / \mathrm{m}^{2}$, or obese: $\geq 30 \mathrm{~kg} / \mathrm{m}^{2}$ ). Participants were told that these measurements aimed at calculating their energy needs. They were asked to complete a web-validated self-administrated $\mathrm{FFQ}^{(45)}$ to measure usual dietary intake. Results of the FFQ were merged with those calculated with the Harris-Benedict's formula (i.e. FFQ (kJ $(\mathrm{kcal}))+(655.1+(9.56 \times$ weight $(\mathrm{kg}))+(1.85 \times$ height $(\mathrm{cm}))-(4.68 \times$ age $($ years $))) \times$ activity factor $) / 2)$ in order to estimate participants' energy needs. The activity factor was based on the reported weekly physical activities of each participant. This estimation was then used to adjust the amount of food provided so that participants received an ad libitum menu that corresponded to $150 \%$ of their estimated daily energy requirements. As all participants were asked to bring back the leftovers, intake was calculated by weighting all foods before $v$. after consumption (note that participants were not aware that leftovers were being weighted; they were told that leftovers were looked at as an additional indicator of the appreciation of the meals). All recipes were standardised, and therefore energy content was calculated using nutritional values from the Canadian Nutrient File ${ }^{(46)}$ or from food product labels. Averaged energy intakes over $10 \mathrm{~d}$ were calculated separately for breakfast, lunch entrée, lunch sides, dinner and total daily intake.

\section{Appetite perceptions}

Throughout the 10-d experimental period, participants were asked to record their AP immediately before and after each meal (i.e. breakfast, lunch and dinner) on $150 \mathrm{~mm}$ visual analogue scales ${ }^{(47)}$. For that purpose, two questions were asked: 'How hungry do you feel?' (not hungry at all - very hungry); and 'How full do you feel?' (not full at all - very full). Appetite ratings before meals were referred to as fasting $\mathrm{AP}$, whereas hunger and fullness ratings after meals were considered as post-meal AP (i.e. in response to the meal consumption). Satiety efficiency was assessed by using the satiety quotient (SQ), as adapted from Green et al. ${ }^{(48)}$. In the present study, the post-meal AP were rated only once (immediately after the meal), which contrast with multiple measures typically used (e.g. every $10 \mathrm{~min}$ for a 1 -h period after the meal) ${ }^{(48-50)}$. This adjustment was necessary because of the study design that did not allow such detailed measurement (e.g. participants ate their meals away from the laboratory, they ate a total of thirty meals in $10 \mathrm{~d}$, and were blinded to the study objective). The SQ values were multiplied by 100 in order to obtain a more meaningful range of values, as previously published $^{(49,50)}$. The SQ was thus calculated for the two AP using the following equation:

$\mathrm{SQ}(\mathrm{mm} / 418 \cdot 4 \mathrm{~kJ}(100 \mathrm{kcal}))=\left(\frac{\text { fasting AP}- \text { post-meal AP }}{\text { energy content of the meal }(\mathrm{kJ}(\mathrm{kcal}))}\right) \times 100$

In the result section, absolute values of SQ are used, which means that a higher SQ for any of the two AP under study represents greater satiety efficiency per energy. SQ has been previously associated with energy intake and is considered as a valid indicator of satiety efficiency ${ }^{(50)}$. The $10-\mathrm{d}$ mean fasting hunger and fullness perceptions, as well as the 10-d mean SQ for hunger and fullness, were calculated for lunch and dinner meals to assess the effect of the nutritional labelling on AP for the targeted meal (i.e. lunch) and for subsequent food intake (i.e. dinner).

\section{Attitudes towards meals offered}

During the 10-d experimental period, participants were also asked to rate their opinion about each tested meal entrée (i.e. breakfast, lunch and dinner), on eight-point Likert scales. The perceived healthiness of the meals offered was thus evaluated by the following question: 'How healthy is this meal for you?' (very unhealthy (1) to very healthy (8)). Participants were also asked to rate their appreciation of each entrée on eight-point Likert scales. As the participants were blinded to the study objectives, they were asked to rate their attitudes towards each entrée, even though only lunch meal entrée's evaluations were analysed.

\section{Questionnaires}

At the end of the experimental period $(T=2)$, participants were asked to complete different questionnaires including sociodemographic, the Restraint Scale ${ }^{(51,52)}$ and the Intuitive Eating Scale ${ }^{(53)}$. At this time, they were also questioned in order to make sure that they actually saw the labels on the lunch meals, and were asked their opinion regarding the objective of the study, as a manipulation check. Finally, they were informed of the real objectives of the study and provided a second written consent to allow the use of the collected data. 


\section{Statistical analyses}

On the basis of a Cohen's $d$ estimate of $0 \cdot 35$, which represents an effect size (ES) defined as small ${ }^{(54)}$, power calculations using G*PowerNT statistical software (version 3.1.0) indicated that a sample size of $n 144$ allows the detection of significant differences with an $\alpha$ level of 0.05 and a power (1- $\beta$ error probability) of $0 \cdot 90$. MIXED models for repeated measures were used to compare the impact of the three experimental labelling groups on mean daily energy intake, $\mathrm{AP}$ and attitudes towards food over the 10-d period, among the whole sample. In all models, experimental labelling groups and days were treated as fixed effects and subject as random effect. To assess the secondary objectives, interactions between experimental labelling groups and BMI categories (normal weight $v$. obese), and between experimental groups and time periods (first $v$. last $3 \mathrm{~d}$ of the 10- $\mathrm{d}$ feeding period), were assessed for energy intake, AP and attitudes towards food. Because we have used a 7-d cycling menu, the comparison of average values in two time periods, namely, days 1-3v. days 8-10, enabled the assessment of the cumulative exposure to the labels over a 1-week period. To ensure the most adequate statistical fit of the models, the structure of the covariance matrix for each outcome variable was taken into account in all analyses. The Tukey's adjustment was used to account for multiple comparisons within each analysis. The ES of the study outcomes were calculated using the Cohen's $d$ formula. Baseline characteristics between groups were compared using the generalised linear model procedure. All variables were normally distributed, and thus no data transformation was needed. Differences at $P<0.05$ were considered significant. All statistical analyses were performed using the Statistical Analysis Software (SAS) version 9.2 (SAS Institute).

\section{Results}

After randomisation, $n 46$ women were allocated to the low-fat label group ( $n 23$ normal weight and 23 obese), $n 48$ to the energy label group ( $n 25$ normal weight and 23 obese) and $n 47$ to the no-label group ( $n 22$ normal weight and 25 obese). Baseline characteristics for experimental labelling groups and BMI categories are shown in Table 1. There were significant between-group differences for age and estimated daily energy requirements despite randomisation. Considering that these variables can influence the primary outcomes, age and estimated energy requirements were consequently added as covariates in all analyses. Energy intake at lunch was also adjusted for energy consumed at breakfast, and energy intake at dinner was adjusted for energy consumed at lunch. SQ were adjusted for fasting AP.

\section{Primary outcome: energy intake}

Nutritional labelling on the lunch entrée had a small, but nonsignificant, effect on 10-d mean energy intake from the lunch entrée (see Table 2). Nutritional labelling on the lunch entrée had no impact on energy intake from the lunch sides or later during the day, as assessed by ad libitum intakes at dinner.
There was a small, but non-significant, difference between labelling groups in overall daily total energy intake.

No interaction was observed between experimental labelling groups and BMI categories for the 10-d mean energy intake for the lunch entrée $\left(F_{2,1250}=1 \cdot 00 ; \quad P=0 \cdot 37\right)$, lunch sides $\left(F_{2,1250}=0.41 ; P=0.67\right)$, dinner $\left(F_{2,1251}=1.30 ; P=0.27\right)$ and whole day intake $\left(F_{2,1249}=0.54 ; P=0.58\right)$. There was also no significant interaction between experimental labelling groups and time (mean of days $1-3 v$. mean of days $8-10$ ) for the $3-\mathrm{d}$ mean energy intake for the lunch entrée $\left(F_{2,691}=1 \cdot 46 ; P=0 \cdot 23\right)$, lunch sides $\left(F_{2,691}=0.30 ; \quad P=0.74\right)$, dinner $\quad\left(F_{2,693}=0.73\right.$; $P=0.48)$ and whole day $\left(F_{2,691}=0 \cdot 26 ; P=0 \cdot 77\right)$.

\section{Secondary outcome: appetite perceptions}

For the whole sample, a small and significant experimental labelling group effect was observed for the 10-d mean fasting hunger perception, where significantly higher hunger perception was reported in the low-fat label group compared with the energy label and the no-label groups (see Table 2). No difference was observed for the 10-d mean fasting fullness perception. Small but non-significant effects of experimental labelling groups on 10-d mean SQ for hunger and for fullness was observed. With regard to the $\mathrm{AP}$ at the subsequent meal (i.e. dinner), no significant difference between the three labelling groups was noted for the $10-\mathrm{d}$ mean fasting hunger perception, fasting fullness perception, SQ for hunger and SQ for fullness (all $P>0 \cdot 05$ ).

No interaction between experimental labelling groups and BMI categories was observed for the 10-d mean fasting hunger perception $\left(F_{2,1236}=0.69 ; P=0.50\right)$, fasting fullness perception $\left(F_{2,1147}=0.74 ; P=0.48\right)$, SQ for hunger $\left(F_{2,1223}=1.46 ; P=0.23\right)$ and for the SQ for fullness $\left(F_{2,1133}=2 \cdot 06 ; P=0 \cdot 13\right)$. No main effect of experimental labelling groups by time (mean of days $1-3 v$. mean of days $8-10)$ interaction was observed for the 3 -d mean fasting hunger $\left(F_{2,686}=0.45 ; P=0.63\right)$ and fullness perceptions $\left(F_{2,628}=0.86 ; P=0.41\right)$, and for the 3 -d mean SQ for fullness $\left(F_{2,617}=1 \cdot 36 ; P=0 \cdot 26\right)$. However, a significant experimental labelling group by time interaction was observed for the 3-d mean SQ for hunger $\left(F_{2,676}=3 \cdot 10 ; P=0 \cdot 046\right.$, see Fig. 1). Specifically, the 3 -d mean SQ for hunger in the energy label group was significantly lower at days 8-10 (10.3 (sD 5.3$) \mathrm{mm} / 418.4 \mathrm{~kJ}(100 \mathrm{kcal}))$ compared with days $1-3(11.0$ (SD 4.8$) \mathrm{mm} / 418.4 \mathrm{~kJ}$ (100 kcal)), whereas no difference was observed in the low-fat label and no-label groups.

\section{Secondary outcome: attitudes towards food}

The rating of attitudes towards the lunch meals offered showed that the 10-d mean appreciation and healthiness perception were not significantly different between experimental labelling groups (see Table 2). No experimental labelling group by BMI interaction was observed for the appreciation $\left(F_{2,1241}=0 \cdot 27\right.$; $P=0.77)$ and the healthiness perception of the lunch meals $\left(F_{2,1098}=1.30 ; P=0.27\right)$. No experimental labelling group by time interaction was observed for the two attitudes $\left(F_{2,689}=0.60 ; P=0.55\right.$ for appreciation; $F_{2,547}=0.16 ; P=0.85$ for healthiness perception). 
Table 1. Baseline characteristics of the sample

(Mean values and standard deviations; numbers and percentages)

\begin{tabular}{|c|c|c|c|c|c|c|c|c|c|c|c|c|}
\hline \multirow[b]{3}{*}{ Baseline characteristics } & \multicolumn{4}{|c|}{ Low-fat label } & \multicolumn{4}{|c|}{ Energy label } & \multicolumn{4}{|c|}{ No label } \\
\hline & \multicolumn{2}{|c|}{ Normal weight ( $n$ 23) } & \multicolumn{2}{|c|}{ Obese ( $n$ 23) } & \multicolumn{2}{|c|}{ Normal weight ( $n$ 25) } & \multicolumn{2}{|c|}{ Obese ( $n$ 23) } & \multicolumn{2}{|c|}{ Normal weight ( $n$ 22) } & \multicolumn{2}{|c|}{ Obese ( $n$ 25) } \\
\hline & Mean & SD & Mean & SD & Mean & SD & Mean & SD & Mean & SD & Mean & SD \\
\hline Age (years) ${ }^{*}$ & $43 \cdot 5^{a}$ & $10 \cdot 8$ & $52 \cdot 3^{b}$ & 11.5 & $37 \cdot 7^{a}$ & $12 \cdot 6$ & $46 \cdot 0^{\mathrm{b}}$ & $14 \cdot 3$ & $42 \cdot 6^{a}$ & $12 \cdot 4$ & $53 \cdot 0^{\mathrm{b}}$ & 11.0 \\
\hline $\mathrm{BMI}\left(\mathrm{kg} / \mathrm{m}^{2}\right)$ & $22 \cdot 4^{\mathrm{a}}$ & 1.6 & $34.7^{\mathrm{b}}$ & 3.9 & $21 \cdot 8^{\mathrm{a}}$ & 1.9 & $34.5^{\mathrm{b}}$ & 4.9 & $22 \cdot 8^{\mathrm{a}}$ & 1.5 & $32 \cdot 6^{\mathrm{b}}$ & $2 \cdot 3$ \\
\hline Daily energy requirements $(\mathrm{kJ}) \dagger$ & $8884 \cdot 2^{a}$ & 709.8 & $10184 \cdot 4^{\mathrm{b}}$ & $971 \cdot 2$ & $9143 \cdot 5^{a}$ & 658.5 & $10486 \cdot 9^{b}$ & $1278 \cdot 3$ & $8856 \cdot 5^{\mathrm{a}}$ & 700.5 & $9926 \cdot 7^{\mathrm{b}}$ & $817 \cdot 8$ \\
\hline Daily energy requirements (kcal) & $2123 \cdot 4$ & $169 \cdot 7$ & $2434 \cdot 1$ & 232.1 & $2185 \cdot 4$ & 157.4 & $2506 \cdot 4$ & 305.5 & $2116 \cdot 8$ & $167 \cdot 4$ & 2372.5 & $195 \cdot 5$ \\
\hline Intuitive eating scoreł & $3 \cdot 4^{\mathrm{a}}$ & 0.5 & $3.1^{\mathrm{b}}$ & 0.4 & $3.5^{\mathrm{a}}$ & 0.5 & $3.1^{\mathrm{b}}$ & 0.6 & $3 \cdot 3^{\mathrm{a}}$ & 0.7 & $3 \cdot 2^{\mathrm{b}}$ & 0.5 \\
\hline \multirow[t]{2}{*}{ Restraint score§ } & $11 \cdot 7^{\mathrm{a}}$ & $3 \cdot 7$ & $14 \cdot 8^{\mathrm{b}}$ & 3.7 & $10 \cdot 4^{\mathrm{a}}$ & $3 \cdot 6$ & $16 \cdot 0^{b}$ & 4.9 & $13 \cdot 0^{a}$ & $5 \cdot 2$ & $15 \cdot 4^{\mathrm{b}}$ & 3.8 \\
\hline & $n$ & $\%$ & $n$ & $\%$ & $n$ & $\%$ & $n$ & $\%$ & $n$ & $\%$ & $n$ & $\%$ \\
\hline \multicolumn{13}{|l|}{ Occupational status\| } \\
\hline Student & 2 & $8 \cdot 7$ & 1 & 4.4 & 5 & $20 \cdot 0$ & 1 & 4.4 & 3 & 13.6 & 0 & 0 \\
\hline Worker & 18 & $78 \cdot 3$ & 9 & 39.1 & 16 & 64.0 & 16 & $69 \cdot 6$ & 15 & $68 \cdot 2$ & 14 & $56 \cdot 0$ \\
\hline Unemployed/retired & 3 & $13 \cdot 0$ & 10 & 43.5 & 4 & $16 \cdot 0$ & 6 & $26 \cdot 1$ & 4 & $18 \cdot 1$ & 9 & $36 \cdot 0$ \\
\hline \multicolumn{13}{|l|}{ Highest level of education } \\
\hline Elementary school & 1 & 4.4 & 0 & 0 & 0 & 0 & 0 & 0 & 0 & 0 & 1 & 4.0 \\
\hline High school & 2 & 8.7 & 6 & $26 \cdot 1$ & 2 & 8.0 & 0 & 0 & 2 & $9 \cdot 1$ & 6 & 24.0 \\
\hline College & 8 & 34.8 & 4 & $17 \cdot 4$ & 6 & $24 \cdot 0$ & 10 & 43.5 & 2 & $9 \cdot 1$ & 8 & $32 \cdot 0$ \\
\hline University & 12 & $52 \cdot 2$ & 11 & 47.8 & 12 & 48.0 & 13 & $56 \cdot 5$ & 18 & $81 \cdot 8$ & 9 & $36 \cdot 0$ \\
\hline \multicolumn{13}{|l|}{ Family income $(C A \$)^{* *}$} \\
\hline 0-19999 & 1 & 4.4 & 1 & 4.4 & 2 & 8.0 & 1 & 4.4 & 2 & $9 \cdot 1$ & 3 & $12 \cdot 0$ \\
\hline $20000-39999$ & 3 & $13 \cdot 0$ & 1 & 4.4 & 1 & 4.0 & 1 & 4.4 & 6 & $27 \cdot 3$ & 3 & $12 \cdot 0$ \\
\hline $40000-59999$ & 2 & $8 \cdot 7$ & 8 & 34.8 & 8 & $32 \cdot 0$ & 5 & 21.7 & 3 & $13 \cdot 6$ & 5 & $20 \cdot 0$ \\
\hline $60000-79999$ & 5 & $21 \cdot 7$ & 1 & 4.4 & 3 & $12 \cdot 0$ & 2 & 8.7 & 4 & $18 \cdot 2$ & 3 & $12 \cdot 0$ \\
\hline $80000-99999$ & 1 & 4.4 & 4 & 8.7 & 2 & 8.0 & 3 & 13.0 & 2 & 9.1 & 3 & $12 \cdot 0$ \\
\hline$\geqslant 100000$ & 6 & $26 \cdot 1$ & 3 & 13.0 & 4 & $16 \cdot 0$ & 8 & 34.8 & 4 & $18 \cdot 2$ & 5 & $20 \cdot 0$ \\
\hline
\end{tabular}

a,b Mean values within a row with unlike superscript letters were significantly different.

the low-fat label and the no-label groups $(P=0.0149)$

† Daily energy requirements of participants in the energy label group are significantly higher than participants in the no-label group $(P=0.0206)$.

¥ Missing values of prefer not to answer (low-fat, obese: $n 1$; no label, obese: $n 1$ ).

$\S$ Missing values of prefer not to answer (low-fat, obese: $n$ 1, energy, obese: $n$ 1; no label, obese: $n 4$ ).

Missing values $n$.

** Missing values of prefer not to answer (low-fat, normal weight: $n$ 5; low-fat, obese: $n$ 5; energy, normal weight: $n$; energy, obese: $n 3$; no label, normal weight: $n 1$; no label, obese: $n 3$ ). 
Table 2. Energy intake, appetite perceptions and attitudes towards food according to experimental labelling groups (Mean values and standard deviations)

\begin{tabular}{|c|c|c|c|c|c|c|c|}
\hline \multirow[b]{2}{*}{ Experimental labelling groups } & \multicolumn{2}{|c|}{ Low-fat label } & \multicolumn{2}{|c|}{ Energy label } & \multicolumn{2}{|c|}{ No label } & \multirow[b]{2}{*}{$F ; P\left(\mathrm{ES}^{\star}\right)$} \\
\hline & Mean & SD & Mean & SD & Mean & SD & \\
\hline 10-d mean lunch entrée intake ( $\mathrm{kJ}$ ) & $1689 \cdot 5^{\mathrm{a}}$ & $542 \cdot 8$ & $1636 \cdot 3^{a}$ & $535 \cdot 6$ & $1564 \cdot 9^{\mathrm{a}}$ & $513 \cdot 0$ & $F_{2,1250}=1.76 ; P=0.17(\mathrm{ES}=0.24) \dagger$ \\
\hline 10-d mean lunch entrée intake (kcal) & $403 \cdot 8$ & $129 \cdot 7$ & $391 \cdot 1$ & $128 \cdot 0$ & $374 \cdot 0$ & $122 \cdot 6$ & \\
\hline 10-d mean lunch sides intake (kJ) & $501 \cdot 6^{a}$ & $357 \cdot 3$ & $483 \cdot 8^{a}$ & $339 \cdot 6$ & $504 \cdot 9^{a}$ & $362 \cdot 0$ & $F_{2,1250}=0.68 ; P=0.51(\mathrm{ES}=0.06)$ \\
\hline 10-d mean lunch sides intake (kcal) & $119 \cdot 9$ & 85.4 & $115 \cdot 6$ & $81 \cdot 2$ & $120 \cdot 7$ & 86.5 & \\
\hline 10-d mean dinner intake $(\mathrm{kJ})$ & $3863 \cdot 0^{\mathrm{a}}$ & $947 \cdot 2$ & $3869 \cdot 0^{a}$ & $967 \cdot 7$ & $3894 \cdot 2^{a}$ & 923.0 & $F_{2,1251}=0.15 ; P=0.86(E S=0.03)$ \\
\hline 10-d mean dinner intake (kcal) & 923.3 & $226 \cdot 4$ & $924 \cdot 7$ & $231 \cdot 3$ & $930 \cdot 4$ & $220 \cdot 6$ & \\
\hline 10-d mean daily intake (kJ) & $10594 \cdot 8^{a}$ & $1940 \cdot 0$ & $10651 \cdot 4^{a}$ & $2130 \cdot 0$ & $10247 \cdot 1^{a}$ & 2013.9 & $F_{2,1249}=0.67 ; P=0.51(\mathrm{ES}=0.20) \dagger$ \\
\hline 10-d mean daily intake (kcal) & $2532 \cdot 2$ & 463.7 & $2545 \cdot 8$ & $509 \cdot 1$ & $2449 \cdot 1$ & $481 \cdot 3$ & \\
\hline 10-d mean fasting hunger perception (mm) & $121 \cdot 4^{\mathrm{a}}$ & $28 \cdot 7$ & $110 \cdot 3^{b}$ & $33 \cdot 7$ & $112 \cdot 1^{\mathrm{b}}$ & $32 \cdot 1$ & $F_{2,1236}=5.63 ; P=0.0037(E S=0.36) \dagger$ \\
\hline 10-d mean fasting fullness perception (mm) & $30 \cdot 5^{\mathrm{a}}$ & $31 \cdot 7$ & $37 \cdot 7^{\mathrm{a}}$ & $32 \cdot 9$ & $36 \cdot 7^{\mathrm{a}}$ & $32 \cdot 5$ & $F_{2,1147}=1.85 ; P=0.16(\mathrm{ES}=0.22) \dagger$ \\
\hline 10-d mean SQ for hunger (mm/418.4 kJ (100 kcal)) & $12 \cdot 3^{\mathrm{a}}$ & $4 \cdot 6$ & $10 \cdot 5^{\mathrm{a}}$ & $5 \cdot 1$ & $11 \cdot 6^{\mathrm{a}}$ & $5 \cdot 3$ & $F_{2,1223}=1.58 ; P=0.21(E S=0.37) \dagger$ \\
\hline 10-d mean SQ for fullness $(\mathrm{mm} / 418.4 \mathrm{~kJ}(100 \mathrm{kcal}))$ & $10 \cdot 8^{a}$ & $5 \cdot 1$ & $9 \cdot 6^{a}$ & $5 \cdot 4$ & $10 \cdot 3^{a}$ & $5 \cdot 9$ & $F_{2,1133}=0.09 ; P=0.92(E S=0.23) \dagger$ \\
\hline 10-d mean appreciation & $6 \cdot 2^{\mathrm{a}}$ & $1 \cdot 3$ & $6 \cdot 2^{a}$ & 1.4 & $6 \cdot 1^{\mathrm{a}}$ & 1.4 & $F_{2,1241}=0.14 ; P=0.87(\mathrm{ES}=0.07)$ \\
\hline 10-d mean perceived healthiness & $6 \cdot 3^{a}$ & $1 \cdot 2$ & $6 \cdot 3^{a}$ & $1 \cdot 3$ & $6 \cdot 4^{a}$ & $1 \cdot 3$ & $F_{2,1098}=0.07 ; P=0.94(E S=0.08)$ \\
\hline
\end{tabular}

$E S$, effect size; $S Q$, satiety quotient.

${ }^{a, b}$ Mean values within a row with unlike superscript letters were significantly different $(P<0.05)$.

* The ES is comparing means from the low-fat $v$. energy label conditions. Values were calculated using the following formula: Cohen's $d=M_{1}-M_{2} / \mathrm{SD}_{\mathrm{pooled}}$, where $\mathrm{SD}_{\mathrm{pooled}}=$ $\sqrt{ }\left(\left(\mathrm{SD} 1^{2}+\mathrm{SD} 2^{2}\right) / 2\right)$. A Cohen's $d$ between 0.2 and 0.49 represents a small ES, between 0.5 and 0.79 a moderate ES and $\geq 0.8$ a large ES $\dagger$ Small ES.

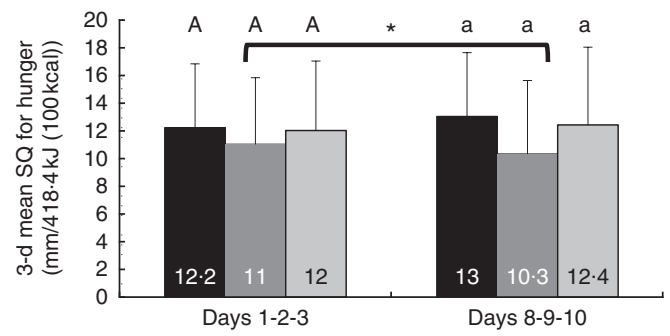

Fig. 1. 3-d mean satiety quotient (SQ) for hunger: experimental labelling groups by time interaction. ${ }^{A, a}$ Mean values with unlike letters were significantly different. ${ }^{*} P<0 \cdot 05$. Values are means, and standard deviations represented by vertical bars. $\square$, Low-fat label; $\square$, energy label; $\square$, no label.

\section{Discussion}

We believe that this is the first study to report the impact of nutritional labels on longer-term food intake. Our data indicate that being exposed to a low-fat or energy label at lunch for $10 \mathrm{~d}$ has no significant impact on energy intake and attitudes towards food. However, data also suggest that the exposition to a low-fat label could increase fasting hunger perceptions.

\section{Energy intake}

In contrast to our study, McCann et $a l^{(12)}$ demonstrated that men ate visibly more in the presence of low percentage of fat/low energy label. Further studies exploring why men and women may respond differently to food labels are urgently needed. Meanwhile, Aaron et al. ${ }^{(55)}$ observed that energy and fat content posting, in a cafeteria context, significantly increased energy intake, among men and women, and more particularly among unrestrained eaters. It has been previously shown that low-fat foods are perceived as lower in energy ${ }^{(11)}$, are more socially acceptable ${ }^{(12)}$, can reduce the guilt associated with eating $^{(11)}$ and can increase the portion considered as appropriate $^{(56)}$. However, it is possible that nutritional labelling may influence food perceptions while having no impact on food consumption ${ }^{(34)}$. As individuals are likely to underestimate the energy content of restaurant meals by $50 \%{ }^{(57)}$, some researchers have suggested that posting energetic information on menus could be considered as a useful strategy to help reducing food intake ${ }^{(58)}$. In the present study, a small but nonsignificant difference in intake was found between the energy label $v$. no-label groups for the lunch meal entrée. Girz et al. ${ }^{(59)}$ reported that perceptions of food healthfulness could be a decisive factor in the amount of food eaten by participants when exposed to energy labelling. The fact that participants in the present study did not differ in the healthiness perception could be one of the reasons explaining the absence of difference in the intake ${ }^{(59)}$, as energy posting is more likely to influence energy intake when energy information is in discordance with participants' expectations. It would be relevant to conduct future controlled experiments in a real-life restaurant setting (e.g. menu choices, energy content indicated for dish served), in which the meals' energy content would be higher than in the present study.

In accordance with Hoefkens et al. ${ }^{(60)}$, the present results indicated that participants did not eat more at dinner after a lunch meal with $v$. without label. However, these findings differ from many other studies ${ }^{(38,61,62)}$ possibly because of the fact that previous studies either only partially controlled (non-imposed home meals) or used buffets that both allowed the possibility for participants to compensate with the foods they actually wanted to eat. In the present study, participants did not have the choice of what to eat, which may explain why they seemed less likely to compensate ${ }^{(63)}$. Moreover, our study differs from the others with its 10-d design, which can partly explain the mixed results. However, it cannot be ruled out that exposure to nutritional labelling in general might not influence later food intake.

In accordance with Steenhuis et al. ${ }^{(64)}$ and Gravel et al. ${ }^{(34)}$, our results indicate that weight status has no influence on how 
food labels affect food intake. This is inconsistent, however, with data from other studies from Wansink \& Chandon ${ }^{(11)}$ and McCann et al. ${ }^{(12)}$. The mixed results found in the literature can be partly explained by the variance in type of food offered (i.e. snacks ${ }^{(11,34,64)}$ or whole meals $\left.{ }^{(12)}\right)$. There is a need for additional studies to more clearly delineate the potential interaction between labelling and weight status as it pertains to energy intake in contexts of a snack or a whole meal, as well as over several days.

Finally, the impact of nutritional labelling was not different between conditions according to habituation (first $3 \mathrm{~d} v$. last $3 \mathrm{~d}$ of exposure). As no effect of experimental labelling groups on intake was observed overall, it is not surprising that no groups by time interaction was observed. To our knowledge, no other study has assessed the impact of labelling on such a period of time (i.e. $10 \mathrm{~d}$ ).

\section{Appetite perceptions}

Contrary to our prediction, small but non-significant effects were observed between nutritional labelling groups for the 10-d mean SQ for both hunger and fullness among women. A small and significant effect of experimental labelling groups was, however, observed, as it pertains to fasting hunger perception, but not for the fasting fullness perception. This result differs from our prediction, as we had predicted a lower satiety efficiency in the lowfat label group but observed an increased fasting hunger. This result would mean that a low-fat label seems to alter the state in which one initiates a meal. However, given that energy intake and SQ did not significantly differ between experimental labelling groups, we could propose that the effect of the low-fat label on the fasting perceptions does not seem to be related to adverse consequences (e.g. overeating). It cannot although be ruled out that the absence of adverse consequences might be because of the design of the study, where participants were not allowed to choose their food.

The results of the present study suggest that weight status does not influence the way nutritional labelling affects AP. As shown in Table 1, obese participants had lower intuitive eating scores and higher restraint scores at baseline than normal-weight participants. We could have expected that restraint eaters would have rated their hunger and fullness perceptions according to what they thought was the appropriate way to answer in line with normative cues ${ }^{(65)}$, instead of relying on their physical sensations, as proposed by the intuitive eating concept ${ }^{(53)}$. Restrained subjects, who have a more 'external' eating regulation ${ }^{(51)}$, could thus be expected to be more easily influenced by nutritional labels. Our results are in discordance with Green et $a l^{(48)}$ who reported that restrained eaters found lower-energy lunches more satiating per unit of energy than the higher-energy lunches.

We observed that the energy-labelled meals were perceived less satiating in the last days compared with the first days according to the SQ for hunger. One cannot help but wonder whether this observation could have been the result of habituation (i.e. decrease in responsiveness upon repeated exposure) to the labels or to meals on days $1-3$ and days $8-10$ (at a 1-week interval). Epstein et al. ${ }^{(41)}$ tested the habituation to the same meal, presented either daily for 5 consecutive days or weekly for 5 weeks (once a week) among obese and non-obese individuals. Whereas a habituation was observed with the daily consumption, there was no indication of long-term habituation for the weekly exposition. It would thus be reasonable to assume that the differences observed in SQ for hunger were not because of the repetition of the meals, but because of the daily presentation of the labels.

To our knowledge, no study has yet evaluated the influence of nutritional labelling at one meal on hunger and fullness perceptions at a subsequent meal. Results from the present study suggest that the low-fat claim and the energy label presented on lunch meals have no impact on the perceptions of hunger and fullness at the subsequent meal (i.e. dinner), in women over a $10-\mathrm{d}$ period. Our results are in accordance with Higgs, (66) works on the memory and its role in appetite regulation, where hunger and satiety perceptions do not seem to be influenced by the previous eating episode. In that study, immediately before a taste test, participants were asked whether to think of the food eaten in the previous meal or to think of about anything they wanted. Even if the participants in the first group did eat significantly less of the tested food, no difference was observed in the rating of their appetite sensations.

\section{Appreciation and healthiness perception}

Contrary to the initial predictions, attitudes towards food were not influenced by nutritional labelling. These results differ from those obtained in earlier studies, which suggested that a food product labelled with a health claim is usually perceived as healthier ${ }^{(34-37)}$. Furthermore, as explained by the "unhealthy= tasty intuition, ${ }^{,(67)}$, foods that are considered as being healthier are often perceived as less tasty. However, according to Wansink et al. ${ }^{(68)}$, a 'health label' on a 'hedonic' food product is more likely to influence one's perceptions than the same label posted on a 'utilitarian' food. Thus, studies using entrées and side dishes that are considered as relatively nutritious are less likely to detect significant differences between label conditions $^{(69)}$. However, in the present study, nutritious meals were used in order to be in line with the mock objective of the study (i.e. rating the appreciation of a new 7-d cyclic menu over a $10-d$ period). In addition, it appears that consumers are more likely to seek for nutrition information on food products considered as healthier ${ }^{(70)}$, which supported our choice of offering relatively healthy meals.

\section{Strength and limitations}

The strengths of this study, such as a 10-d exposure to nutritional labelling and the consumption of all foods in each participant's own environment as opposed to a laboratory setting, are not without certain limitations. Results from this study need to be interpreted in the context of a relatively educated population, with half of the women having a university degree compared with $28 \%$ of the Canadian population $^{(71)}$. Whether results apply to populations with a lower degree of education needs further investigation. In a review of the literature on nutritional labelling, Cowburn \& Stockley ${ }^{(4)}$ concluded that consumers with lower levels of 
education and income are more likely to have difficulties in understanding nutritional labelling. Moreover, the study has been conducted in the Institute of Nutrition and Functional Foods, which is well known in the Quebec City vicinity for the studies it performs related to health and nutrition. There is a possibility that the women recruited had particular interest towards nutrition, being possibly more knowledgeable and critical about nutritional labelling. Another limitation of this study is the fact that the SQ for hunger and fullness was not assessed using multiple measures over time as it was done in other studies ${ }^{(48-50)}$. Using multiple measures of AP after the meals would have enabled us to explore the possibility to observe immediate post-ingestion effects that are different from the effects produced later. Furthermore, as it was not possible for us to respect an ad libitum context because the meals were eaten at home, we gave food that covered $150 \%$ of the participants' daily needs. Women had the possibility to eat as much or as less as they wanted, and they ate on average $68 \%$ of the food provided (from 25 to $100 \%$ ). However, in real life, most eating occasions are terminated through environmental cues such as portion size, and it is common to finish the plate ${ }^{(63)}$. We cannot ignore the fact that some participants may have eaten all the food offered because of portion size cues and not because they were influenced by the labels, and that portion size cues may have a different impact according to weight status.

\section{Conclusions}

This study contributes to the literature by enhancing the understanding of the impact of nutritional labelling on energy intake, AP and attitudes. Data suggest that different types of food labelling do not significantly influence energy intake and attitudes towards foods over a $10-\mathrm{d}$ period. However, a low-fat label seems to increase fasting hunger perception in women. We also addressed the impact of a 10-d exposure to nutritional labelling on habituation to labels regarding energy intake, AP and attitudes towards foods. Contrary to many studies, we explored these issues in a more 'real life' context. Similar studies should also be undertaken in men and women to assess sex comparison. It would also be interesting to examine whether an intervention on the recognition of hunger and satiety sensations (intuitive eating) leads to different results concerning the influence of nutritional labelling. It is important to note that small ES were observed for both intake and AP. As reported previously $^{(72)}$, a small difference of $418 \mathrm{~kJ}$ daily can make a difference on weight gain prevention over years. Considering the small but non-significant differences observed in the present study (e.g. 404 more kJ daily in energy label $v$. no label) over a $10-d$ period, these findings still stress the need to conduct further studies in various settings in order to address the public health relevance of nutritional labelling strategies.

\section{Acknowledgements}

The authors express their gratitude to the participants for their involvement in the study, as well as to the members of the research team who have helped to conduct the study (Cynthia
Donaldson, Sandra Gagnon, Lyson Gélinas, Martin Gravel, Valérie Lamontagne, Steeve Larouche and Julie Maltais-Giguère).

The present study was supported by a grant from Canadian Institutes of Health Research (CIHR) (grant no. MOP-110951). B. L. is Chair of Nutrition at Laval University.

V. P., B. L., V. D. and E. D. contributed in designing the study and formulating the research questions. V. P., S. P., J. P. and E. C. were responsible in carrying out the study. E. C., V. P. and J. P. analysed the data and wrote the article. All co-authors revised the final version of the paper.

There are no conflicts of interest.

\section{Supplementary material}

For supplementary material/s referred to in this article, please visit http://dx.doi.org/doi:10.1017/S0007114515003918

\section{References}

1. Health Canada (2003) Food and Drugs Act, Health Canada, Ottawa, ON

2. Food and Drug Administration (2009) Food labeling guide. Ottawa, ON: Food and Drug Administration.

3. Health Canada (2013) Food and nutrition - food labelling. College Park, MD: Health Canada.

4. Cowburn G \& Stockley L (2005) Consumer understanding and use of nutrition labelling: a systematic review. Public Health Nutr 8, 21-28.

5. Hawley KL, Roberto CA, Bragg MA, et al. (2013) The science on front-of-package food labels. Public Health Nutr 16, 430-439.

6. Schermel A, Emrich TE, Arcand J, et al. (2013) Nutrition marketing on processed food packages in Canada: 2010 Food Label Information Program. Appl Physiol Nutr Metab 38, 666-672.

7. Farley T, Caffarelli A, Bassett M, et al. (2009) New York city's fight over calorie labeling. Health Aff 28, w1098-w109.

8. Food Standards Agency (2009) Calorie labelling and nutrition information in catering, Food Standards Agency, London.

9. Commonwealth of Australia (2011) Labelling Logic - Review of Food Labelling Law and Policy. Canberra: Commonwealth of Australia.

10. Provencher V, Polivy J \& Herman CP (2009) Perceived healthiness of food. If it's healthy, you can eat more! Appetite $\mathbf{5 2}$, 340-344.

11. Wansink B \& Chandon P. (2006) Can 'low fat' nutrition labels lead to obesity? J Mark Res XLIII, 605-617.

12. McCann MT, Wallace JM, Robson PJ, et al. (2013) Influence of nutrition labelling on food portion size consumption. Appetite 65, 153-158

13. Ebneter DS, Latner JD \& Nigg CR (2013) Is less always more? The effects of low-fat labeling and caloric information on food intake, calorie estimates, taste preference, and health attributions. Appetite 68, 92-97.

14. Stubenitsky K, Aaron J, Catt S, et al. (2000) The influence of recipe modification and nutritional information on restaurant food acceptance and macronutrient intakes. Public Health Nutr 3, 201-209.

15. Kiszko KM, Martinez OD, Abrams C, et al. (2014) The influence of calorie labeling on food orders and consumption: a review of the literature. J Commun Health 39, 1248-1269.

16. Sinclair SE, Cooper M \& Mansfield ED (2014) The influence of menu labeling on calories selected or consumed: a systematic review and meta-analysis. J Acad Nutr Diet 114, 1375-1388 e15. 
17. Stran KA \& Knol LL (2013) Determinants of food label use differ by sex. J Acad Nutr Diet 113, 673-679.

18. Bleich SN \& Pollack KM (2010) The publics' understanding of daily caloric recommendations and their perceptions of calorie posting in chain restaurants. BMC Public Health 10, 121.

19. Satia JA, Galanko JA \& Neuhouser ML (2005) Food nutrition label use is associated with demographic, behavioral, and psychosocial factors and dietary intake among African Americans in North Carolina. J Am Diet Assoc 105, 392-402; discussion 3.

20. Stubbs RJ, Hughes DA, Johnstone AM, et al. (2000) The use of visual analogue scales to assess motivation to eat in human subjects: a review of their reliability and validity with an evaluation of new hand-held computerized systems for temporal tracking of appetite ratings. Br J Nutr $\mathbf{8 4}$, $405-415$.

21. Doucet E, St-Pierre S, Almeras N, et al. (2003) Relation between appetite ratings before and after a standard meal and estimates of daily energy intake in obese and reduced obese individuals. Appetite 40, 137-143.

22. Flint A, Raben A, Blundell JE, et al. (2000) Reproducibility, power and validity of visual analogue scales in assessment of appetite sensations in single test meal studies. Int J Obes Relat Metab Disord 24, 38-48.

23. Porrini M, Crovetti R, Testolin G, et al. (1995) Evaluation of satiety sensations and food intake after different preloads. Appetite 25, 17-30.

24. Barkeling B, Rossner S \& Sjoberg A (1995) Methodological studies on single meal food intake characteristics in normal weight and obese men and women. Int J Obes Relat Metab Disord 19, 284-290.

25. Finkelstein SR \& Fishbach A (2010) When healthy food makes you hungry. J Consum Res 37, 357-367.

26. Oakes ME (2006) Filling yet fattening: stereotypical beliefs about the weight gain potential and satiation of foods. Appetite 46, 224-233.

27. Barkeling B, King NA, Naslund E, et al. (2007) Characterization of obese individuals who claim to detect no relationship between their eating pattern and sensations of hunger or fullness. Int J Obes (Lond) 31, 435-439.

28. Blundell JE \& Gillett A (2001) Control of food intake in the obese. Obes Res 9, Suppl. 4, 263S-270S.

29. Cornier MA, Grunwald GK, Johnson SL, et al. (2004) Effects of short-term overfeeding on hunger, satiety, and energy intake in thin and reduced-obese individuals. Appetite 43, 253-259.

30. Drapeau V, Blundell JE, Gallant AR, et al. (2013) Behavioural and metabolic characterisation of the low satiety phenotype. Appetite 70, 67-72.

31. Wansink B, Payne CR \& Chandon P (2007) Internal and external cues of meal cessation: the French paradox redux? Obesity (Silver Spring) 15, 2920-2924.

32. Tuomisto T, Tuomisto MT, Hetherington M, et al. (1998) Reasons for initiation and cessation of eating in obese men and women and the affective consequences of eating in everyday situations. Appetite 30, 211-222.

33. Contento IR (2008) Nutrition education: linking research, theory, and practice. Asia Pac J Clin Nutr 17, Suppl. 1, 176-179.

34. Gravel K, Doucet E, Herman CP, et al. (2012) 'Healthy,' 'diet,' or 'hedonic'. How nutrition claims affect food-related perceptions and intake? Appetite 59, 877-884.

35. Aschemann-Witzel J \& Hamm U (2010) Do consumers prefer foods with nutrition and health claims? Results of a purchase simulation. J Mark Commun 16, 47-58.

36. Kozup JC, Creyer EH \& Burton S (2003) Making healthful food choices: the influence of health claims and nutrition information on consumers' evaluations of packaged food products and restaurant menu items. J Mark 67, 19-34.

37. van Trijp HC \& van der Lans IA (2007) Consumer perceptions of nutrition and health claims. Appetite 48, 305-324.

38. Chandon P \& Wansink B (2007) The biasing health halos of fast-food restaurant health claims: lower calorie estimates and higher side-dish consumption intentions. J Consum Res $\mathbf{3 4}$, 301-314.

39. Bowen D, Green P, Vizenor N, et al. (2003) Effects of fat content on fat hedonics: cognition or taste? Physiol Behav 78, $247-253$.

40. Roefs A \& Jansen A (2004) The effect of information about fat content on food consumption in overweight/obese and lean people. Appetite 43, 319-322.

41. Epstein LH, Carr KA, Cavanaugh MD, et al. (2011) Long-term habituation to food in obese and nonobese women. Am J Clin Nutr 94, 371-376.

42. Epstein LH, Fletcher KD, O'Neill J, et al. (2013) Food characteristics, long-term habituation and energy intake. Laboratory and field studies. Appetite 60, 40-50.

43. Myers Ernst M \& Epstein LH (2002) Habituation of responding for food in humans. Appetite 38, 224-234.

44. Condrasky M, Ledikwe JH, Flood JE, et al. (2007) Chefs' opinions of restaurant portion sizes. Obesity (Silver Spring) 15, 2086-2094

45. Labonte ME, Cyr A, Baril-Gravel L, et al. (2012) ) Validity and reproducibility of a web-based, self-administered food frequency questionnaire. Eur J Clin Nutr 66, 166-173.

46. Health Canada (2010) Canadian Nutrient File (www. healthcanada.gc.ca/cnf).

47. Hill AJ \& Blundell JE (1986) The effects of a high-protein or high-carbohydrate meal on subjective motivation to eat and food preferences. Nutr Behav 3, 133-144.

48. Green SM, Delargy HJ, Joanes D, et al. (1997) A satiety quotient: a formulation to assess the satiating effect of food. Appetite 29, 291-304.

49. Drapeau V, King N, Hetherington M, et al. (2007) Appetite sensations and satiety quotient: predictors of energy intake and weight loss. Appetite 48, 159-166.

50. Drapeau V, Blundell J, Therrien F, et al. (2005) Appetite sensations as a marker of overall intake. Br J Nutr 93, 273-280.

51. Herman CP \& Mack D (1975) Restrained and unrestrained eating. J Pers 43, 647-660.

52. Herman CP \& Polivy J (1980) Restrained eating. In Obesity, pp. 208-225 [A Stunkard, editor]. Philadelphia, PA: W.B. Saunders.

53. Tylka TL (2006) Development and psychometric evaluation of a measure of intuitive eating. J Couns Psychol 53, 226-240.

54. Cohen J (1992) A power primer. Psychol Bull 112, 155-159.

55. Aaron JI, Evans RE \& Mela DJ (1995) Paradoxical effect of a nutrition labelling scheme in a student cafeteria. Nutr Res $\mathbf{1 5}$, 1251-1261.

56. Chan C, Patch C \& Williams P (2005) Australian consumers are sceptical about but influenced by claims about fat on food labels. Eur J Clin Nutr 59, 148-151.

57. Burton S, Creyer EH, Kees J, et al. (2006) Attacking the obesity epidemic: the potential health benefits of providing nutrition information in restaurants. Am J Public Health 96 , 1669-1675.

58. Bassett MT, Dumanovsky T, Huang C, et al. (2008) Purchasing behavior and calorie information at fast-food chains in New York City, 2007. Am J Public Health 98, 1457-1459.

59. Girz L, Polivy J, Herman CP, et al. (2012) The effects of calorie information on food selection and intake. Int J Obes (Lond) 36, 1340-1345. 
60. Hoefkens C, Lachat C, Kolsteren P, et al. (2011) Posting pointof-purchase nutrition information in university canteens does not influence meal choice and nutrient intake. Am J Clin Nutr 94, 562-570.

61. Roberto CA, Larsen PD, Agnew H, et al. (2010) Evaluating the impact of menu labeling on food choices and intake. $A m \mathrm{~J}$ Public Health 100, 312-318.

62. Shide DJ \& Rolls BJ (1995) Information about the fat content of preloads influences energy intake in healthy women. $J \mathrm{Am}$ Diet Assoc 95, 993-998.

63. Blundell J, de Graaf C, Hulshof T, et al. (2010) Appetite control: methodological aspects of the evaluation of foods. Obes Rev 11, 251-270.

64. Steenhuis IHM, Kroeze W, Vyth EL, et al. (2010) The effects of using a nutrition logo on consumption and product evaluation of a sweet pastry. Appetite 55, 707-709.

65. Herman $\mathrm{CP} \&$ Polivy J (2005) Normative influences on food intake. Physiol Behav 86, 762-772.

66. Higgs S (2002) Memory for recent eating and its influence on subsequent food intake. Appetite 39, 159-166.

67. Raghunathan R, Naylor RW \& Hoyer WD (2006) The unhealthy $=$ tasty intuition and its effects on taste inferences, enjoyment, and choice of food products. J Mark 70, 170-184.
68. Wansink B, van Ittersum K \& Painter JE (2004) How diet and health labels influence taste and satiation. J Food Sci 69 , S340-S346.

69. Kahkonen P, Tuorila H \& Lawless H (1997) Lack of effect of taste and nutrition claims on sensory and hedonic responses to a fat-free yogurt. Food Qual Prefer 8, 125-130.

70. Grunert KG, Wills JM \& Fernandez-Celemin L (2010) Nutrition knowledge, and use and understanding of nutrition information on food labels among consumers in the UK. Appetite $\mathbf{5 5}$ 177-189.

71. Statistics Canada (2012) Niveau de scolarité de la population âgée de 25 à 64 ans, population autochtone hors réserve, population non-autochtone, et population totale, Canada, provinces et territoires, 2009, 2010, 2011 et 2012 (Educational attainment of the population aged 25 to 64 years, off-reserve Aboriginal, non-Aboriginal, and total population, Canada, provinces and territories, 2009, 2010, 2011 and 2012). Ottawa, ON: Statistics Canada.

72. Hill JO (2009) Can a small-changes approach help address the obesity epidemic? A report of the Joint Task Force of the American Society for Nutrition, Institute of Food Technologists, and International Food Information Council. Am J Clin Nutr 89, 477-484. 